\title{
Laparoscopic management of a large torted ovarian cyst in an adolescent virgin: a case report
}

This article was published in the following Dove Press journal:

International Journal of Women's Health

14 May 2012

Number of times this article has been viewed

\author{
Mohamed Sabry 1,2 \\ Abdou S Ait Allah' \\ Eman Roshdy ${ }^{2,3}$ \\ Ayman Al-Hendy ${ }^{2}$ \\ 'Department of Obstetrics and \\ Gynecology, Sohag Faculty of \\ Medicine, Sohag University, Sohag, \\ Egypt; ' ${ }^{2}$ epartment of Obstetrics \\ and Gynecology, Center for \\ Women's Health Research, Meharry \\ Medical College, Nashville, TN, USA; \\ ${ }^{3}$ Department of Public Health and \\ Community Medicine, Sohag Faculty \\ of Medicine, Sohag University, Sohag, \\ Egypt
}

Correspondence: Ayman Al-Hendy Department of Obstetrics and Gynecology, Center for Women's Health Research, Meharry Medical College, 1005 Dr DB Todd Jr Blvd, Nashville, TN 37208, USA

Tel +l 6159633107

Fax +l 6159633125

Email ahendy@mmc.edu
Abstract: We report a case of a torted mature cystic teratoma in a 23-year-old, sexually inactive, virgin female which necessitated immediate laparoscopy. The patient and her family stressed that the integrity of the hymen must be maintained at any cost, for cultural reasons. We opted out of our routine intravaginal preparation for laparoscopic surgery to honor the patient's request to maintain the integrity of the hymen. Left salpingo-oophorectomy was accomplished, and the specimen was removed using a large nephrectomy endobag. Here, we describe techniques that are useful for this procedure, including the use of gauze attached to ovum forceps to manipulate the uterus through the rectum, and a review of the literature.

Keywords: ovarian teratoma, large torted cyst, virgin female, laparoscopic management, cultural sensitivity, treatment option

\section{Case report}

A 23-year-old virgin female of Iraqi descent and Islamic faith presented at the Obstetrics and Gynecology Clinic, Meharry Medical College, Nashville, TN, in November 2010. Her chief complaint was a dull pain in the left lower abdominal/pelvic region. Her cycles were regular and average in amount with no complaints of menorrhagia or dysmenorrhea. Her last menstrual period had occurred 16 days earlier.

Her past medical history was noncontributory. She was generally healthy, had undergone no previous surgery, and had not suffered previously from abdominal or pelvic pain. She had reached menarche at the age of 14 years. The patient was accompanied by her mother who voiced that her daughter was still a virgin and because of their cultural values regarding virginity, any proposed management must preserve the integrity of her daughter's hymen. The patient weighed $76 \mathrm{~kg}$ and was $167 \mathrm{~cm}$ in height, with a pulse rate of 82 beats/minute, temperature $98.1^{\circ} \mathrm{F}$, blood pressure $100 / 68 \mathrm{mmHg}$. An abdominal examination showed a fullness/mass of the left hypochondrium and slight tenderness on palpation. No signs of peritoneal irritation were noted.

Sonography and computed tomography (CT) enabled us to diagnose the mass provisionally. An abdominal ultrasound revealed a cyst that most probably originated from the left ovary. This cyst was about $9 \times 7.5 \times 11 \mathrm{~cm}$ and showed variable echogenicity. A transvaginal ultrasound was declined because of the patient's virginity. Neither ascites nor free abdominal fluid accumulations were noticed. CT revealed an $8.5 \times 8 \times 12 \mathrm{~cm}$ cystic mass originating from the left ovary. The cyst contained nondependent intracystic spheres of lipid material, favoring the diagnosis of a cystic teratoma. Laboratory results showed a normal full blood count, negative urinary 
beta human chorionic gonadotrophin, serum beta human chorionic gonadotrophin at $2.4 \mathrm{mIU} / \mathrm{L}$ (normal nonpregnant value $<3 \mathrm{mIU} / \mathrm{L}$ ), and inhibin levels at $13.5 \mathrm{pg} / \mathrm{mL}$ (normal early luteal phase is $16-98 \mathrm{pg} / \mathrm{mL}$ ).

The patient was then counseled and scheduled for a laparoscopic left ovarian cystectomy and a possible left salpingo-oophorectomy. Again, the patient and her family stressed that maintaining her virginity was a priority, even if that meant converting from laparoscopy to laparotomy. Two days later, while awaiting her elective surgical appointment, the patient called in about sudden onset of severe lower abdominal pain that had started 2-3 hours earlier. The patient was instructed to go to the emergency room immediately. Three hours later, the patient presented with acute abdomen, a temperature of $38^{\circ} \mathrm{C}$, nausea, and vomiting. A full blood count and urine tests were within normal limits. Immediate surgery was planned to treat the suspected left adnexal torsion.

After general anesthesia was induced, we carefully and gently examined the patient's vaginal area and found it to be almost completely sealed, with a microperforate hymen containing a hymenal opening that would not fit even one finger without disturbing the hymen. To fulfill the patient's request to maintain her virginity, we asked the circulating nurse to be extra careful around the vulvar area and not to perform the routine intravaginal part of surgical preparation to avoid disturbing the hymen. We positioned the patient in the dorsal supine position instead of the typical dorsal lithotomy position for laparoscopy. After placing the trocars and panoramically viewing the abdominal cavity (Figure 1), we used a $5 \mathrm{~mm}$ probe to stent and antivert the uterus, and we also used a self-locking atraumatic grasper to handle the uterus carefully as needed. We found a left ovarian cyst torted $\times 3$ (Figure 1, panel A). Because we lacked the option of a uterine manipulator, we raised the intra-abdominal pressure to $22 \mathrm{mmHg}$ to generate additional room for intraabdominal manipulation and then used a $5 \mathrm{~mm}$ laparoscopic uterine probe to manipulate the uterus during the procedure. After finding the right ovary and tube to be normal (Figure 1, panel B), we untwisted the cyst and started to perform the cystectomy. However, we soon observed some hair and decided to proceed instead with a left salpingo-oophorectomy so as to avoid possible puncture of a dermoid cyst, which could cause chemical peritonitis and affect the patient's future fertility potential. The left adnexa, which were about $11 \times 13 \mathrm{~cm}$ upon intraoperative assessment (Figure 1A), did not fit into the normally available endobag, so we used a large nephrectomy bag to remove the specimen from the abdominal cavity. We used the nephrectomy bag through a $10 \mathrm{~mm}$ central port, and for visualization, we switched to a $5 \mathrm{~mm}$ laparoscope through one of the two $5 \mathrm{~mm}$ lateral ports. At the end of the procedure, we noticed that the patient was experiencing moderate bilateral periorbital air emphysema, and although periorbital edema is a rare observation with our surgical team, it likely to have been caused by a combination of relatively high intra-abdominal pressure and a steep Trendelenburg position. However, the periorbital emphysema resolved spontaneously over the next few hours. The patient was kept under observation for 23 hours and then discharged in excellent condition.

Her postoperative course was uneventful. The gross pathology evaluation of the cyst revealed a $9 \times 8 \times 12.5 \mathrm{~cm}$ cyst containing hair, fat globules, and three teeth. The ovary also measured approximately $6 \times 4 \times 2 \mathrm{~cm}$ in its largest dimensions, with smaller cystic lesions. The microscopic examination confirmed a diagnosis of benign teratoma (dermoid cyst).

\section{Discussion}

Ovarian teratoma occurs in a wide range of ages, with a peak during the reproductive years. ${ }^{1}$ It is considered to be the most common ovarian neoplasm in both pediatric and adult populations, ${ }^{2}$ in the first two decades of life, and accounts for more than two-thirds of benign ovarian neoplasms. ${ }^{3,4}$
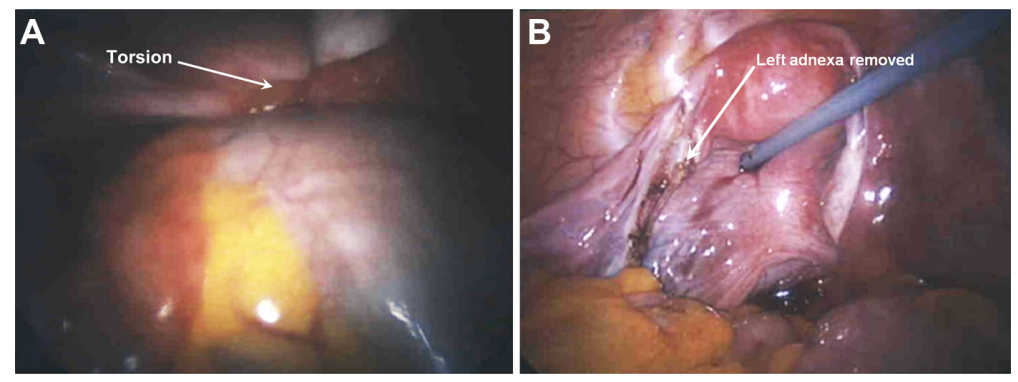

Figure I Panoramic view of the abdominal cavity. Left dermoid cyst torted $\times 3$ (panel A). A view of the pelvis after removal of the left adnexa (panel B). The right adnexa appear normal. 
Among 118 cases with ovarian teratoma, 85.6\% were found to be younger than 40 years. ${ }^{5}$ Another study based on a cohort of 112 patients with mature ovarian teratoma found that the surgeries performed for these patients ranged from unilateral oophorectomy to total hysterectomy with bilateral oophorectomy, and within this group of patients, ovarian function was preserved in $75 \%$ of the patients. ${ }^{6}$

Laparoscopic surgery in adult virgin women is not common in Western communities and is extremely underreported in the medical literature. Intra-abdominal pressure is referred to in the literature as a safe measure to overcome entry-related complications, ${ }^{7}$ and some reports indicate that an increase in intra-abdominal pressure of over $20 \mathrm{mmHg}$ for a period of 5 minutes is associated with changes in heart rate, mean arterial blood pressure, arterial oxygen saturation, and intratracheal pressure that are still within the normal range. ${ }^{8}$ Other reports advocate the use of higher intra-abdominal pressure for additional safety to protect against organ injury because there are no changes in cardiovascular parameters between $15 \mathrm{mmHg}$ and $30 \mathrm{mmHg} .{ }^{9}$ In our case, we found that elevating intra-abdominal pressure to a level of $22 \mathrm{mmHg}$ throughout the procedure was not only a safe measure to avoid entry-related complications but was also a very helpful maneuver to provide additional room to facilitate dealing with the large adnexal lesion laparoscopically in the absence of the intravaginal uterine manipulator (due to the need to preserve virginity).

Other approaches may also be considered. A personal communication with colleagues in the Middle East (where laparoscopic interventions in virgin patients are not uncommon) suggested using gauze attached to ovum forceps to manipulate the uterus via the rectum and may be considered as an alternative technique in such cases.

Laparoscopy is generally a safe procedure, but not free from the complications encountered in $0.1 \%-10 \%$ of cases. ${ }^{10}$ These side effects range from entry injury through to some major side effects, including visceral injury and injury to major blood vessels. Our surgical team followed a combination of increased intra-abdominal pressure and careful intra-abdominal manipulation in addition to the
Trendelenburg position to reduce these possible side effects. To our knowledge and based on a Medline search using the keywords "virgin", "ovarian teratoma", and laparoscopy, there has not been a publication describing the use of laparoscopic intervention for teratoma in virgin patients. Therefore, we feel that our report provides a useful insight in regard to such cases.

\section{Conclusion}

Teratomas in virgin adolescent patients are relatively common, and with globalization, intercultural communication and the trend for immigration from the Middle East to western countries, encountering such cases will become more common for surgeons. Enhancing the knowledge about how to address the cultural needs of such patients is an important part of providing a comprehensive clinical service to an increasingly diverse patient population.

\section{Disclosure}

The authors report no conflicts of interest in this work.

\section{References}

1. Selvaggi SM. Tumors of the ovary, maldeveloped gonads, fallopian tube, and broad ligament. Arch Pathol Lab Med. 2000;124(3):477.

2. Savasi I, Lacy JA, Gerstle JT, Stephens D, Kives S, Allen L. Management of ovarian dermoid cysts in the pediatric and adolescent population. J Pediatr Adolesc Gynecol. 2009;22(6):360-364.

3. Berek JS, Natarajan S. Ovarian and fallopian tube cancer. In: Berek JS, editor. Berek and Novak's Gynecology, 14th ed. Philadelphia, PA: Lippincott Williams and Wilkins; 2007.

4. Azizkhan RG, Caty MG. Teratomas in childhood. Curr Opin Pediatr. 1996;8(3):287-292.

5. Lakkis WG, Martin MC, Gelfand MM. Benign cystic teratoma of the ovary: a 6-year review. Can J Surg. 1985;28(5):444-446.

6. Morillo Conejo M, Martin Canadas F, Munoz Carmona V, et al. Ovarian mature teratoma. Clinico-pathological study of 112 cases and review of the literature. Ginecol Obstet Mex. 2003;71:447-454. Spanish.

7. The ABCs of a safer laparoscopic entry. J Minim Invasive Gynecol. 2006;13(3):249-251.

8. Hypolito OH, Azevedo JL, de Lima Alvarenga Caldeira FM, et al. Creation of pneumoperitoneum: noninvasive monitoring of clinical effects of elevated intraperitoneal pressure for the insertion of the first trocar. Surg Endosc. 2010;24(7):1663-1669.

9. Vilos GA, Vilos AG, Abu-Rafea B, Hollett-Caines J, NikkhahAbyaneh Z, Edris F. Three simple steps during closed laparoscopic entry may minimize major injuries. Surg Endosc. 2009;23(4):758-764.

10. Chandler JG, Corson SL, Way LW. Three spectra of laparoscopic entry access injuries. J Am Coll Surg. 2001;192(4):478-490.
International Journal of Women's Health

\section{Publish your work in this journal}

The International Journal of Women's Health is an international, peerreviewed open-access journal publishing original research, reports, reviews and commentaries on all aspects of women's healthcare including gynecology, obstetrics, and breast cancer. Subject areas include: Chronic conditions (migraine headaches, arthritis, osteoporosis);

\section{Dovepress}

Endocrine and autoimmune syndromes; Sexual and reproductive health; Psychological and psychosocial conditions. The manuscript management system is completely online and includes a very quick and fair peer-review system. Visit http://www.dovepress.com/ testimonials.php to read real quotes from published authors. 